\title{
Incorporação de biomassa de fabáceas ao substrato de plantio para controle da podridão-de-escleródio (Sclerotium rolfsii) em cubiu (Solanum sessiliflorum)
}

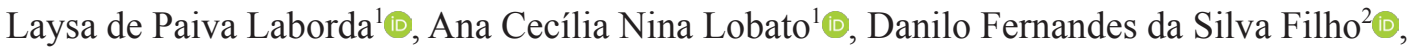 \\ Rosalee Albuquerque Coelho Netto ${ }^{2} \mathbb{0}$
}

\begin{abstract}
${ }^{1}$ Mestranda do Programa de Pós-graduação em Agricultura no Trópico Úmido, pelo Instituto Nacional de Pesquisas da Amazônia (Inpa), Manaus, Amazonas, Brasil, CEP 69067-375. ${ }^{2}$ Coordenação de Sociedade, Ambiente e Saúde, Inpa, CEP 69067-375, Amazonas, Manaus, Brasil. Autora para correspondência: Laysa de Paiva Laborda (laysalaborda@gmail.com)

Data de chegada: 13/02/2018. Aceito para publicação em: 05/02/2019.
\end{abstract}

\section{RESUMO}

Laborda, L.P.; Lobato, A.C.N.; Silva Filho, D.F.; Coelho Netto, R.A. Incorporação de biomassa de fabáceas ao substrato de plantio para controle da podridão-de-escleródio (Sclerotium rolfsii) em cubiu (Solanum sessiliflorum). Summa Phytopathologica, v.45, n.4, p.399-405, 2019.

O cultivo do cubiu (Solanum sessiliflorum Dunal), no Amazonas, é limitado pela alta incidência da doença podridão-de-escleródio (Sclerotium rolfsii Sacc.) e a incorporação de material vegetal ao substrato de cultivo altera a microflora presente. O trabalho objetivou avaliar o potencial de controle da podridãode-escleródio em cubiu por meio de incorporação, ao substrato de cultivo, de biomassa fresca triturada de quatro espécies de fabáceas: Erythrina fusca Loureiro e Senna reticulata (Wild.) Irwin \& Barneby, nativas da Amazônia, e Desmodium heterocarpon (L.) DC. subsp. ovalifolium (Prain) Ohashi e Gliricidia sepium (Jacq.) Walp., exóticas. O substrato foi infestado com 10 $\mathrm{g}$ de arroz colonizado com $S$. rolfsii. $\mathrm{L}^{-1}$ de substrato e incorporadas $40 \mathrm{~g}$ da biomassa das fabáceas. $\mathrm{L}^{-1}$ de substrato em vasos com volume de $8 \mathrm{~L}$ nos quais foram cultivadas mudas de cubiu em viveiro. $\mathrm{O}$ experimento foi em DIC com três repetições e sete tratamentos (quatro espécies de fabáceas e três testemunhas, sem a incorporação de biomassa). Em uma das testemunhas não houve infestação do substrato e em duas, o substrato foi infestado, sendo que em uma, as plantas foram pulverizadas com fungicida. Outro experimento foi realizado avaliando-se o efeito de doses de G. sepium incorporadas ao substrato. O experimento foi em DIC com três repetições e seis tratamentos $\left(40,80,120\right.$ e $160 \mathrm{~g}$ de G. sepium. $\mathrm{L}^{-1}$ de substrato e duas testemunhas sem incorporação de G. sepium sendo que em uma das testemunhas, as plantas foram tratadas com fungicida). Em ambos os experimentos foi avaliada a incidência da doença e a densidade do inóculo no substrato. No primeiro experimento, os dados da área abaixo da curva de progresso da doença foram submetidos à ANOVA e as médias comparadas pelo teste Tukey. No segundo experimento os dados foram submetidos à análise de regressão entre os níveis de biomassa incorporada no substrato. No primeiro experimento a incorporação da biomassa não diferiu do fungicida na redução da incidência da podridão-deescleródio e na supressão da densidade do patógeno. No segundo experimento, a redução da incidência da podridão-de-escleródio foi proporcional da biomassa de G. sepium, apresentando $100 \%$ de controle com a incorporação de $139 \mathrm{~g}$ de G. sepium. $\mathrm{L}^{-1}$ de substrato. A adição de $142 \mathrm{~g}$ de biomassa reduziu a população de $S$. rolfsii no substrato em $20 \%$.

Palavras-chave: Fabaceae, biomassa, controle fitossanitário, fitopatógeno de solo.

\section{ABSTRACT}

Laborda, L.P.; Lobato, A.C.N.; Silva Filho, D.F.; Coelho Netto, R.A. Incorporation of fabaceae biomass into planting substrate for the control of southern blight (Sclerotium rolfsii) in cocona (Solanum sessiliflorum). Summa Phytopathologica, v.45, n.4, p.399-405, 2019.

Cocona (Solanum sessiliflorum Dunal) cultivation in Amazonas State is limited by the high incidence of southern blight (Sclerotium rolfsii Sacc.), and plant material incorporation into the substrate changes the microflora present on it. The objective of this study was to evaluate the control potential of southern blight in cocona by incorporation into the substrate fresh powdered biomass of four Fabaceae species: Erythrina fusca Loureiro and Senna reticulate (Wild.) Irwin \& Barneby, which are native to Amazonia, and Desmodium heterocarpon (L.) DC. subsp. ovalifolium (Prain) Ohashi and Gliricidia sepium (Jacq.) Walp, which are exotic. The substrate was infested with $10 \mathrm{~g}$ rice colonized with $S$. rolfsii. $\mathrm{L}^{-1}$ substrate and $40 \mathrm{~g}$ biomass of Fabaceae. $\mathrm{L}^{-1}$ substrate were incorporated into $8 \mathrm{~L}$ pots, in which cocona seedlings were grown in a nursery. Experimental design was completely randomized, with three replicates and seven treatments (four Fabaceae species and three controls, without biomass incorporation). In one of the controls there was no substrate infestation and in two, the substrate was infested, and in one, the plants were sprayed with fungicide. Another experiment was carried out to evaluate the effect of $G$. sepium doses incorporated into the substrate. The experiment had a completely randomized design with three replicates and six treatments $\left(40,80,120\right.$ and $160 \mathrm{~g} \mathrm{G}$. sepium. $\mathrm{L}^{-1}$ substrate and two controls without $G$. sepium incorporation, and one of these controls had its plants treated with fungicide). In both experiments, the disease incidence and inoculum density in the substrate were evaluated. In the first experiment, the data for the area under the disease progress curve were subject to ANOVA and means were compared according to Tukey's test. In the second experiment, the data were subjected to regression analysis between the levels of biomass incorporated into the substrate. In the first experiment, biomass incorporation did not differ from the fungicide in reducing southern blight incidence and in suppressing the pathogen based on the substrate density. In the second experiment, southern blight incidence reduction was proportional to G. sepium biomass, showing $100 \%$ control with the incorporation of $139 \mathrm{~g}$ G. sepium. $\mathrm{L}^{-1}$ substrate. The biomass of $142 \mathrm{~g}$ reduced $S$. rolfsii population in the substrate by $20 \%$.

Keywords: Fabaceae, biomass, phytosanitary control, soil phytopathogen. 
O cubiu (Solanum sessiliflorum Dunal), solanácea originária da Amazônia, é consumido como alimento, como medicamento, para reduzir níveis elevados de colesterol, ácido úrico e glicose no sangue, e na indústria de cosméticos. Associado aos usos e pelas suas propriedades agronômicas de rusticidade e boa capacidade de produção, o cubiu é um produto com elevado potencial mercadológico (9).

No cultivo do cubiu, uma das doenças mais impactantes é a podridão-deescleródio, cujo agente causal é o fungo habitante de solo Sclerotium rolfsii Sacc., que ocasiona o apodrecimento do colo da planta resultando em sua morte. A doença diminui a produtividade da cultura, podendo chegar a morte das plantas (13) e, frequentemente, ocorre em áreas de produção de solanáceas na Amazônia (4).

$\mathrm{O}$ controle de fitopatógenos habitantes do solo é difícil, devido à grande capacidade de sobrevivência (5). A sobrevivência de $S$. rolfsii, em solo, é prolongada, podendo chegar a até oito anos (6). A incorporação de material vegetal ao solo possibilita a melhoria da fertilidade, fornece nutrientes aos microrganismos controladores biológicos, pode proporcionar a liberação de substâncias tóxicas aos patógenos durante a decomposição da biomassa, e induzir resistência na planta hospedeira $(11,15)$. As fabáceas são frequentemente utilizadas para incorporação ao solo pela frequente ocorrência na natureza, fácil acesso e cultivo, alta produção de biomassa, rusticidade e, principalmente, pela sua capacidade de simbiose com bactérias fixadoras de nitrogênio, como também, apresentam substâncias com potencial de controle de doenças (13).

Em busca de definir um método ambientalmente sustentável, eficiente e de fácil acesso aos agricultores para controle da podridão-de-escleródio em cubiu na Amazônia, o presente trabalho teve como objetivo avaliar o efeito da incorporação de material vegetal das fabáceas nativas da Amazônia, E. fusca e $S$. reticulata, e exóticas, $D$. heterocarpon e $G$. sepium, ao substrato de cultivo, no controle da podridão-de-escleródio em cubiu.

\section{MATERIAL E MÉTODOS}

Os experimentos foram conduzidos no Laboratório de Fitopatologia, Laboratório Temático de Solos e Plantas e viveiro de produção de mudas no Instituto Nacional de Pesquisas da Amazônia (Inpa), em Manaus-AM nos anos de 2016 e 2017.

O isolado de $S$. rolfsii foi obtido a partir de uma planta de cubiu cultivada na Estação Experimental do Ariaú do Inpa, em Iranduba-AM, com sintomas da podridão-de-escleródio. Os escleródios coletados foram desinfestados por duas imersões em álcool $70 \%$ por $45 \mathrm{~s}$, hipoclorito de sódio $1 \%$ por $30 \mathrm{~s}$, e água destilada por 1 min e cultivados em placas de Petri contendo meio de cultura BDA (batata-dextrose-ágar) durante dez dias.

Para infestação do solo com o fungo, o inóculo foi produzido em $5 \mathrm{~kg}$ de arroz sem casca embebidos em $7 \mathrm{~L}$ de água destilada, por $12 \mathrm{~h}$, e escorridos em peneira. Porções de $250 \mathrm{~g}$ de arroz foram esterilizadas em autoclave por 20 min a $120^{\circ} \mathrm{C}$, por dois dias consecutivos, em saco de polipropileno $(25 \mathrm{x}$ $18 \mathrm{~cm}$, espessura de $10 \mu \mathrm{m})$. Para fechamento dos sacos utilizou-se um anel de cano de PVC (40 mm de largura x 38,1 mm de diâmetro) preso com uma liga de borracha na boca do saco e um tampão de algodão fechando a entrada do tubo, coberto por jornal. Após este procedimento, dez discos $(0,5 \mathrm{~cm}$ de diâmetro) de colônia de $S$. rolfsii, cultivada por dez dias em meio BDA, foram transferidos para cada saco de polipropileno contendo arroz autoclavado (4). Os sacos foram mantidos sob temperatura de $26^{\circ} \mathrm{C} \pm 1$ com o conteúdo sendo revolvido diariamente para uniformização do crescimento do fungo até que os grãos estivessem totalmente colonizados, o que ocorreu aos 23 dias de cultivo. Em seguida, o inóculo dos diferentes sacos foi misturado para uniformização.

O material vegetal incorporado ao substrato nos vasos foi constituído pela biomassa fresca de quatro espécies de fabáceas. A biomassa foi constituída de folhas de E. fusca, S. reticulata e G. sepium, e folhas e ramos de D. heterocarpon.
Logo após a coleta, a biomassa foi triturada em processador e armazenada à sombra, por 24 horas, até a incorporação ao substrato dos vasos.

Avaliação da incidência da podridão-de-escleródio em cubiu cultivado em substrato acrescido de quatro espécies de fabáceas

Para o primeiro experimento, iniciado em julho de 2016, vasos plásticos com $8,7 \mathrm{~L}$ de capacidade, foram preenchidos com $8 \mathrm{~L}$ de substrato (argissolo: esterco de galinha, 2:1). A infestação foi feita com a incorporação de $10 \mathrm{~g}$ de arroz colonizado com $S$. rolfsii. $\mathrm{L}^{-1}$ de substrato ou $80 \mathrm{~g}$ do inóculo em cada vaso (1). A população do patógeno foi quantificada aos 20 dias da infestação do substrato (10). Após 20 dias da infestação do substrato, foram incorporados $320 \mathrm{~g}$ da biomassa fresca e triturada ( $40 \mathrm{~g}$ de biomassa. $\mathrm{L}^{-1}$ de substrato) de cada espécie de fabácea ao substrato de cada vaso. Após uma semana deste procedimento, uma muda de cubiu de 8 a $10 \mathrm{~cm}$ de altura (cultivar 8 do Inpa), aos 90 dias da semeadura, foi transplantada para cada vaso. Os vasos permaneceram em viveiro coberto com sombrite ( $50 \%$ de luz incidente) sob irrigação diária no início da manhã e no final da tarde no Campus III do Inpa.

O delineamento experimental foi inteiramente casualizado, com sete tratamentos (quatro espécies de fabáceas incorporadas ao substrato e três testemunhas) e três repetições. A unidade experimental foi constituída de três vasos com uma planta de cubiu em cada. Nas testemunhas não houve incorporação de biomassa das fabáceas ao substrato dos vasos. Na primeira testemunha houve infestação do substrato, na segunda, não houve infestação do substrato, e na terceira, houve infestação do substrato e duas aplicações de fungicida sistêmico (Viper $700^{\circledR}$, tiofanato metílico, Iharabras S.A. Indústrias Químicas, Sorocaba-Brasil) com $9 \mathrm{~mL}$ da solução no colo das plantas de cubiu na concentração de $70 \mathrm{~g}$ (p.c.) por $100 \mathrm{~L}$ de água. A incidência da doença foi avaliada semanalmente contabilizando as plantas com sintomas de necrose e constrição do colo por parcela, até o período de floração. Com os dados foram elaboradas curvas de progresso da doença e calculada a área abaixo da curva de progresso da doença (AACPD) (2). Os dados foram transformados em $\sqrt{ }(x+0,5)$ e submetidos à análise de variância $\mathrm{e}$, quando significativos, submetidos ao teste de separação de média de Tukey a 1\% de probabilidade. As análises estatísticas foram efetuadas utilizando-se o programa Assistat versão 7.7. Ao final do experimento também foi feita a quantificação da população do patógeno no substrato dos vasos.

\section{Avaliação da densidade do inóculo no substrato antes e após a incorporação do material vegetal}

Após 20 dias da infestação do substrato dos vasos, quatro amostras simples do substrato infestado e não infestado contidos nos vasos foram coletadas na profundidade de $10 \mathrm{~cm}$ com um trado de $1 \mathrm{~cm}$ de diâmetro e depois misturadas para formação de duas amostras compostas. Ao final do experimento, foram coletadas quatro amostras simples do substrato dos três vasos de cada repetição, por tratamento. As amostras simples foram misturadas para formação de uma amostra composta por tratamento. O substrato coletado foi seco a sombra durante dois dias e passado em peneira de malha de $2 \mathrm{~mm}$. De cada amostra composta foram retiradas três porções de $25 \mathrm{~g}$ e distribuídas em três placas de Petri de $12 \mathrm{~cm}$ de diâmetro. Sobre o solo contido em cada placa foram vertidos $10 \mathrm{~mL}$ de metanol a $1 \%$ e, após 48 horas, foi feita a contagem de colônias de $S$. rolfsii com auxílio de estereomicroscopio e calculada a média de colônias por grama de solo (10). Os dados foram transformados em $\sqrt{ }(x+0,5)$ e submetidos à análise de variância e ao teste de separação de média de Tukey a $1 \%$ de probabilidade. As análises estatísticas foram efetuadas utilizando-se o programa Assistat versão 7.7.

Para ajuste da metodologia de quantificação do inóculo, foi realizado um teste com adição de 30 escleródios em $25 \mathrm{~g}$ de substrato, com três repetições. As colônias formadas foram quantificadas e a densidade média de inóculo recuperada foi de 20 escleródios, resultando em $66,67 \%$ de eficiência no método de detecção. 
Avaliação da podridão-de-escleródio em cubiu cultivado em solo acrescido com quatro doses de Gliricidia sepium

Para o segundo experimento, iniciado em maio de 2017, os procedimentos realizados foram semelhantes ao primeiro. Vasos plásticos de capacidade de $8,7 \mathrm{~L}$ foram preenchidos com $6 \mathrm{~L}$ de substrato, infestado com $60 \mathrm{~g}$ de arroz colonizado com $S$. rolfsii (10 g. $\mathrm{L}^{-1}$ de substrato), em cada vaso. Aos 20 dias da infestação, a população do patógeno foi quantificada e foram incorporadas as folhas de G. sepium nas proporções de 240, 480, 720 e $960 \mathrm{~g}$ da biomassa fresca triturada, em cada vaso, equivalendo, respectivamente a 40, 80, 120 e $160 \mathrm{~g}$ de biomassa fresca. $\mathrm{L}^{-1}$ de substrato. Após uma semana deste procedimento, uma muda de cubiu foi transplantada para o substrato, em cada vaso em viveiro.

O delineamento experimental foi inteiramente casualizado, com seis tratamentos (quatro doses de biomassa de G. sepium e duas testemunhas), com três repetições e quatro plantas por repetição. Nas duas testemunhas não houve incorporação de biomassa da G. sepium ao substrato dos vasos e, em uma delas, houve duas aplicações de fungicida sistêmico (Viper $700^{\circledR}$ ). Os dados de incidência foram transformados em $\sqrt{ }(\mathrm{x}+0,5)$ e submetidos à análise de regressão a $1 \%$ de probabilidade. As análises estatísticas foram realizadas com auxílio do software Assistat versão 7.7.

\section{RESULTADOS E DISCUSSÃO}

Avaliação da incidência da podridão-de-escleródio em cubiu cultivado em substrato acrescido de quatro espécies de fabáceas

A incidência da doença nos tratamentos com incorporação de todas as espécies de fabáceas foi similar ao tratamento com fungicida, exceto no tratamento com $E$. fusca que teve maior incidência da doença, a qual foi similar a do tratamento com solo infestado.

Há diversos relatos sobre os efeitos benéficos da adubação verde com leguminosas para o aumento da produção em cultivos. Dentre estes efeitos pode-se citar o aumento no teor de matéria orgânica e de nitrogênio, aumento da ciclagem de nutrientes e o controle de pragas e doenças $(14,16)$.

As plantas do gênero Erythrina são ricas em alcalóides e flavonóides e apresentam atividade antifúngica (3). As plantas de cubiu cultivadas em substrato ao qual se adicionaram folhas de E. fusca, no entanto, apresentaram a mais alta incidência de podridão-de-escleródio, quando comparadas às plantas dos demais tratamentos (Figura 1).
Sete dias após o transplante das mudas de cubiu, os sintomas da podridãode-escleródio puderam ser observados em $44,44 \%$ das plantas no substrato com incorporação de E. fusca. Aos 56 dias, $11,11 \%$ das plantas nos tratamentos com G. sepium e S.reticulata apresentaram sintomas. No substrato acrescido de folhas de $D$. heretocarpon as primeiras plantas com sintomas foram observadas aos 91 dias. Neste período (91 dias), 22,22\% das plantas cultivadas no substrato infestado, e 33,33\% das plantas cultivadas no substrato infestado e tratadas com fungicida apresentavam sintomas da doença. Aos 133 dias, última avaliação do experimento, a incidência da podridão-de-escleródio no tratamento onde foi incorporada $E$. fusca e no solo infestado, sem a incorporação de leguminosas, observou-se a maior porcentagem de plantas doentes, $88,89 \%$. Nos tratamentos com $D$. heterocarpon e $S$. reticulata a porcentagem de plantas doentes no final do experimento foi de $77,78 \%$. Nas plantas cultivadas em substrato que recebeu G. sepium a porcentagem de plantas doentes no final do experimento e no tratamento onde se aplicou fungicida foi de $66,67 \%$ (Figura 2).

Os valores das áreas abaixo das curvas de progresso da doença (AACPD) das plantas dos tratamentos onde se incorporaram D. heterocarpon e G. sepium, foram inferiores aos das outras fabáceas e similares ao do tratamento onde as plantas foram tratadas com fungicida (Figura 3).

Erythrina fusca e S. reticulata apresentam atividade antifúngica $(3,7)$, porém, não se observaram diferenças desses tratamentos em relação à redução da incidência da podridão-de-escleródio comparados aos demais (Figura 3). Não se encontraram relatos sobre o uso $E$. fusca, S. reticulata e D. heterocarpon incorporadas ao solo para o controle da podridão-de-escleródio.

Avaliação da densidade do inóculo no substrato antes e após a incorporação do material vegetal no primeiro experimento

Após 20 dias da infestação do substrato com S. rolfsii, a população foi em média 60 escleródios por $100 \mathrm{~g}$ de substrato, considerando a eficiência de $66,67 \%$ do método de detecção usado. Corrigindo para $100 \%$, estavam presentes cerca de 90 escleródios por $100 \mathrm{~g}$ de substrato. No substrato sem infestação, a população de $S$. rolfsii foi zero.

Nos tratamentos com incorporação de fabáceas e nas testemunhas sem incorporação de fabáceas ou com tratamento das plantas com fungicida, o número de escleródios viáveis não diferiu estatisticamente (Figura 4).

A redução da incidência da podridão-de-escleródios nas plantas de cubiu (Figura 1) e da densidade de propágulos de S. rolfsii no substrato (Figura 4) pode ter ocorrido pelo aumento da matéria orgânica, a qual, pode atuar nos

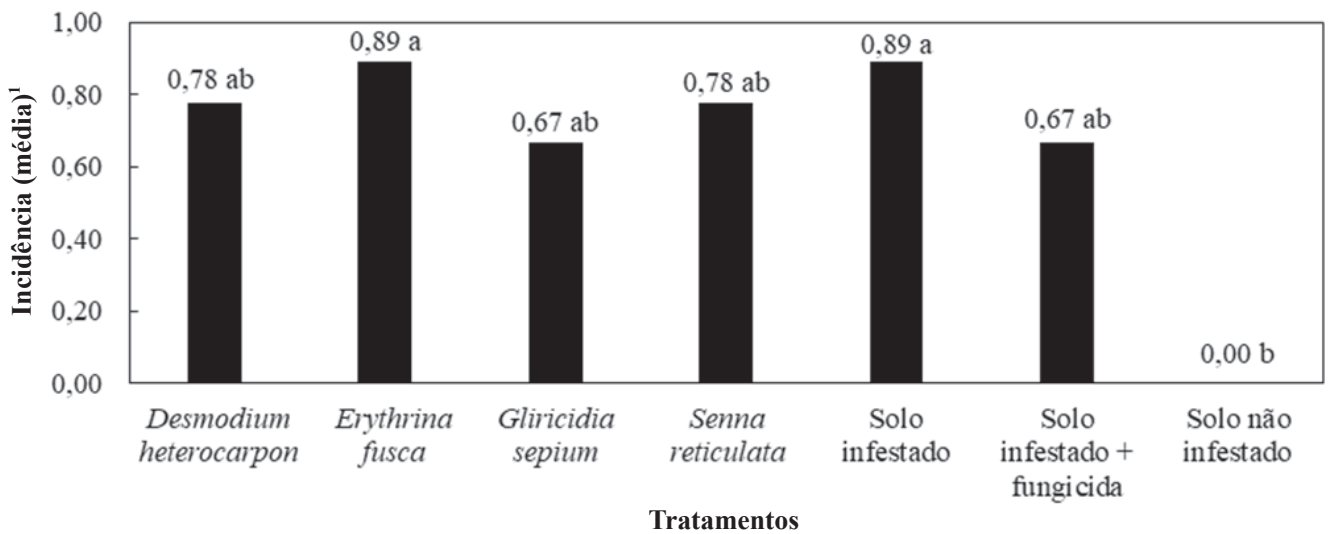

Teste $\mathrm{F} 2,88^{* *}$

Tratamentos

Figura 1. Incidência (\%) média da podridão-de-escleródio em cubiu, aos 133 dias após o transplante, cultivado em substrato infestado com Sclerotium rolfsii na proporção de 120 UFC. $100 \mathrm{~g}$ de substrato $^{-1}$ e acrescido de fabácias ou fungicida (Viper $700^{\circledR}, 70 \mathrm{~g}$ de p.c.100. L-1 de água, duas aplicações de $9 \mathrm{~mL}$.planta ${ }^{-1}$ ). Manaus, Inpa, 2017.

${ }^{1}$ Incidência da doença média de três repetições com três plantas de cubiu por repetição.

${ }^{2}$ Médias seguidas pelas mesmas letras sobre as barras não diferem estatisticamente pelo Teste Tukey ao nível de $5 \%$ de probabilidade $(\mathrm{P}<0,05) ; \mathrm{CV} \%=15,48$. 
fitopatógenos diretamente pela produção de compostos químicos, como ácidos graxos voláteis, ácido nitroso, amônia e isotiocianatos, ou indiretamente favorecendo o aumento da população dos antagonistas tendo assim um efeito indireto na relação patógeno-hospedeira (8). A liberação de metabólitos dos resíduos pode tanto suprimir a população de microrganismos patogênicos, como incrementar a população de antagonistas (19). Diversas espécies de plantas contêm, na parte aérea, compostos nematicidas, bactericidas e fungicidas pré-formados, como alcalóides, ácidos graxos, isotiocianatos, glicosídeos cianogênicos, terpenóides e compostos fenólicos, que podem contribuir para o controle de fitopatógenos, após a incorporação ao substrato (10).

Avaliação da podridão-de-escleródio em cubiu cultivado em solo acrescido com quatro doses de Gliricidia sepium

A relação entre doses de G. sepium e incidência da doença observadas na análise de regressão linear foram significativas $(\mathrm{P} \leq 0,01)$. A incidência de podridão-de-escleródio nas plantas de cubiu foi reduzida com o aumento da quantidade de folhas de G. sepium incorporadas ao substrato. As plantas dos tratamentos com incorporação de $80,120 \mathrm{e} 160 \mathrm{~g}$ de folhas de G. sepium. $\mathrm{L}^{-1}$ substrato apresentaram incidência de podridão-de-escleródio de 17,8 e $0 \%$, respectivamente. A partir da dose de $139 \mathrm{~g}$ de G. sepium a incidência da doença foi $0 \%$. O tratamento sem incorporação de G. sepium apresentou $100 \%$ de incidência (Figura 5).

A adição de extrato etanólico de G. sepium ao meio de cultura inibiu 50\% do crescimento micelial e da produção de escleródios de S. rolfsii in vitro (17). G. sepium apresenta fenóis, alcaloides, flavonoides, saponinas e óleos essenciais como constituintes dos seus metabólitos secundários (18).

Aos 63 dias do transplante se observou $8,33 \%$ de incidência de podridãode-escleródio nas plantas do tratamento sem incorporação de G. sepium e com aplicação de fungicida. Aos 70 dias do transplante, plantas em todos os tratamentos, exceto as do que foram incorporadas $160 \mathrm{~g}$ de G. sepium. $\mathrm{L}^{-1}$ de substrato apresentavam sintomas da doença. As plantas do tratamento desse tratamento não apresentaram sintomas da podridão-de-escleródio até o final

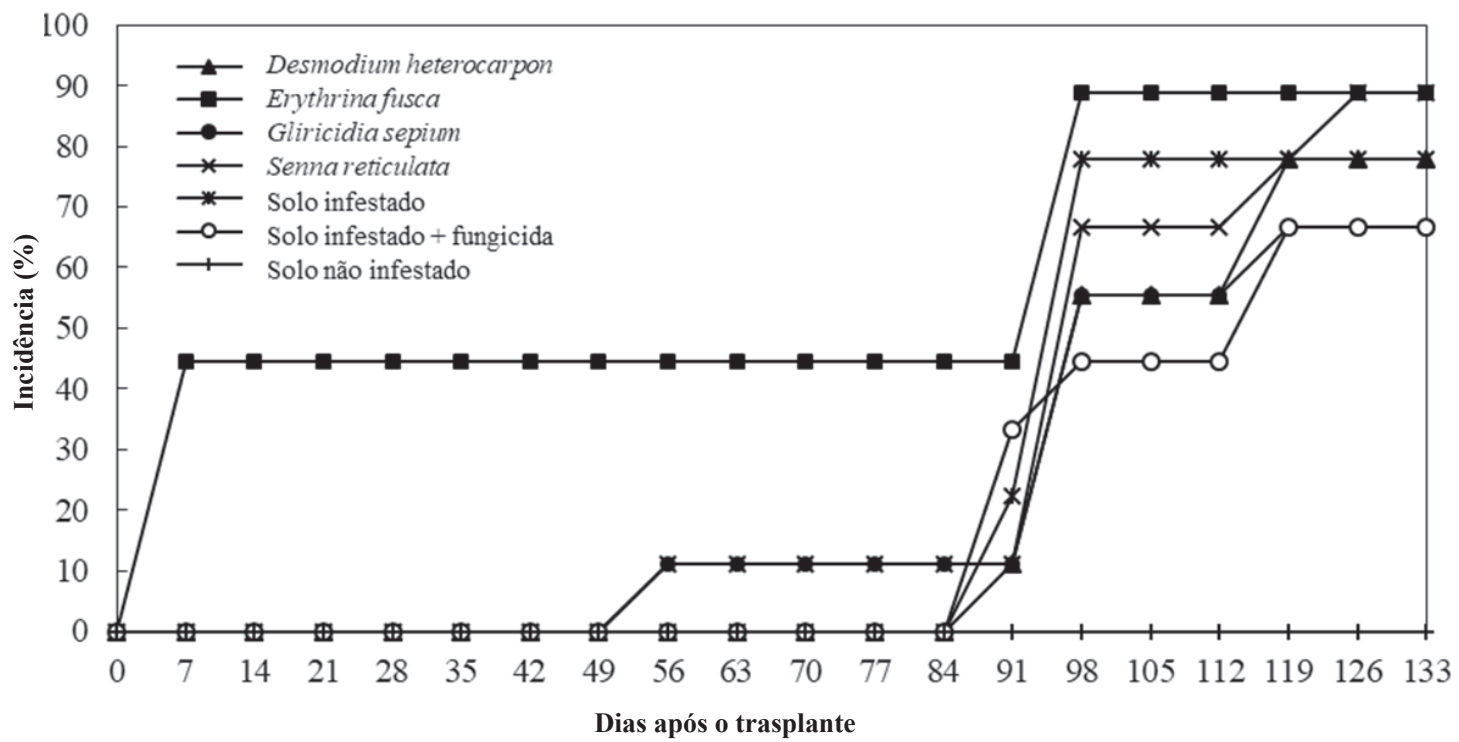

Figura 2. Curvas de progresso da incidência da podridão-de-escleródio em cubiu cultivado em substrato infestado com $10 \mathrm{~g}$ de arroz colonizado por Sclerotium rolfsii.. $\mathrm{L}^{-1}$ de substrato, acrescido de $40 \mathrm{~g} . \mathrm{L}^{-1}$ de folhas de quatro espécies de fabáceas, plantas tratadas com fungicida (Viper $700^{\circledR}$, tiofanato metílico, $70 \mathrm{~g}$ de p.c. 100 . $\mathrm{L}^{-1}$ de água, e duas pulverizações de $9 \mathrm{~mL}$.planta ${ }^{-1}$, com intervalo de 50 dias) e plantas cultivadas em solo não infestado, durante 133 dias. Manaus, Inpa, 2017.

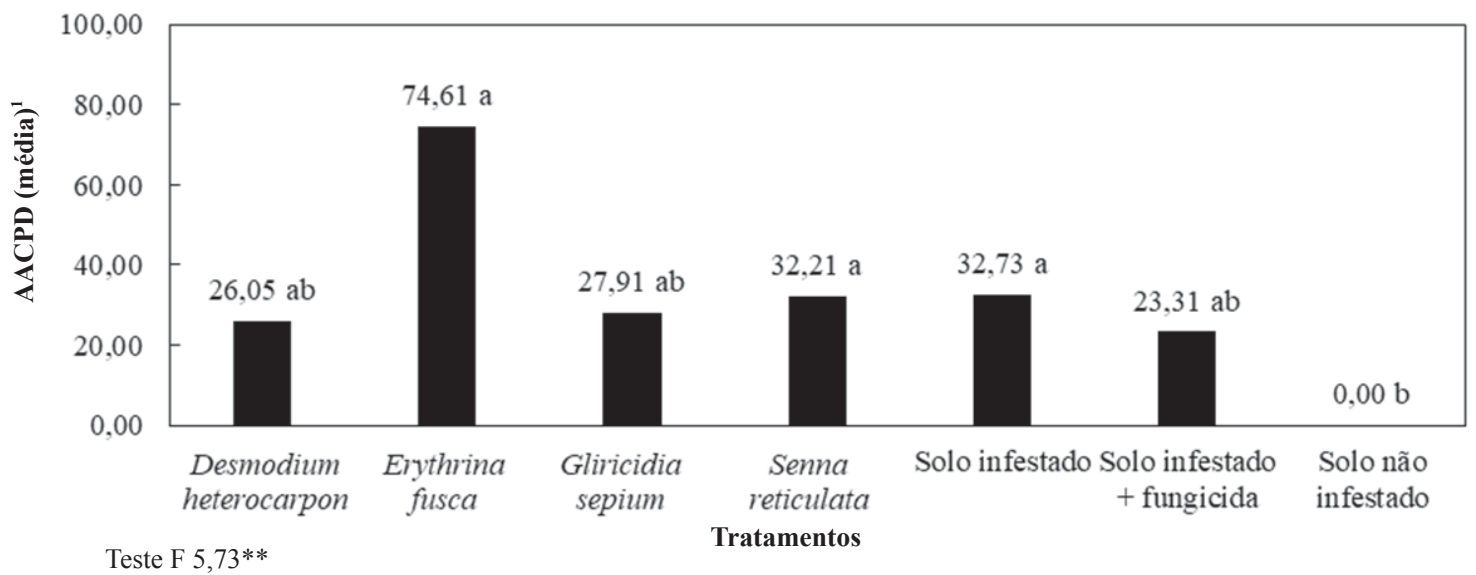

Figura 3. Área abaixo da curva de progresso da doença (AACPD) da podridão-de-escleródio em plantas de cubiu cultivadas em solo infestado com Sclerotium rolfsii (120 UFC.100 g de solo ${ }^{-1}$ ), acrescido ou não de folhas de fabáceas trituradas (40 g.L ${ }^{-1}$ de solo) ou pulverizadas com fungicida Viper $700^{\circledR}(70$ g de p.c. 100 $\mathrm{L}^{-1}$ de água, duas aplicações de $9 \mathrm{~mL}$.planta $\left.{ }^{-1}\right)$. Manaus, Inpa, 2017. ${ }^{1}$ AACPD média de três repetições com três plantas de cubiu por repetição. ${ }^{2}$ Médias seguidas pelas mesmas letras sobre as barras não diferem estatisticamente pelo Teste Tukey, ao nível de $1 \%$ de probabilidade $(\mathrm{P}<0,01) ; \mathrm{CV} \%=33,99$. 


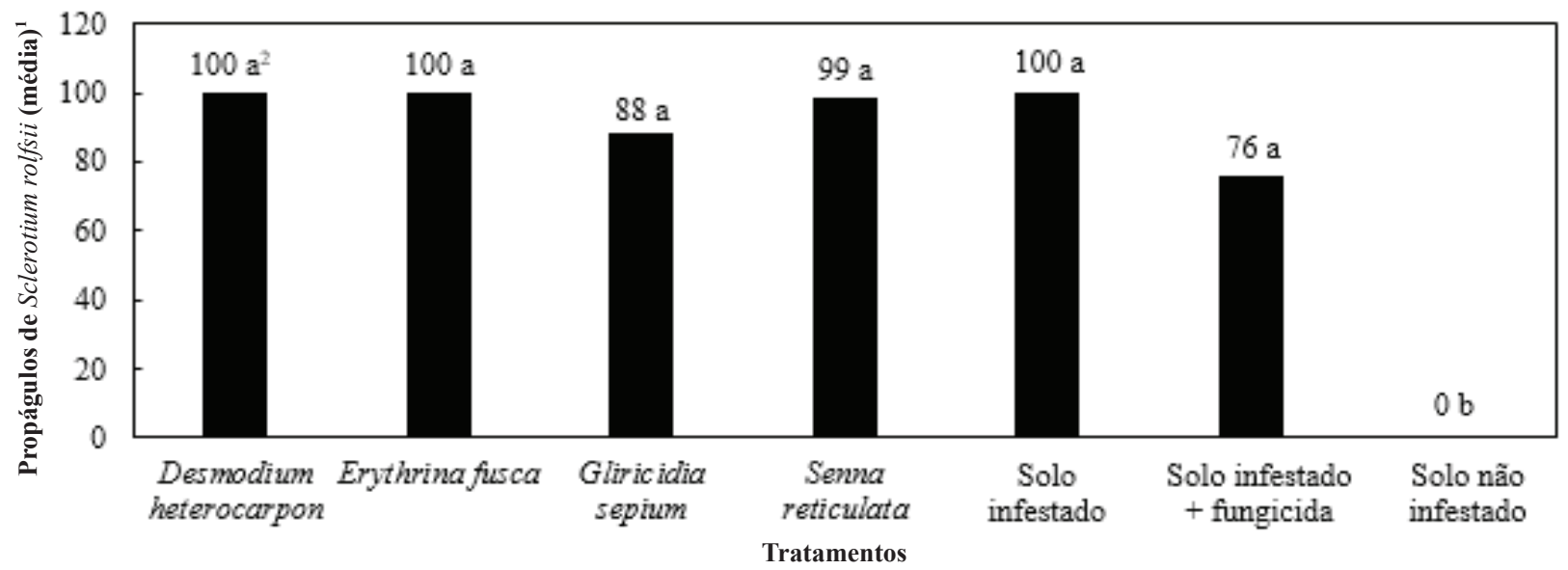

Teste F $57,70 * *$

Figura 4. Número médio de propágulos de Sclerotium rolfsii em $100 \mathrm{~g}$ de substrato nos tratamentos avaliados para controle da podridão-de-escleródio em cubiu, 133 dias após o transplante. Manaus, InpaA, 2017. ${ }^{1}$ Densidade média de colônias de $S$. rolfsii em três repetições. ${ }^{2}$ Médias seguidas pelas mesmas letras sobre as barras não diferem estatisticamente pelo Teste Tukey ao nível de $1 \%$ de probabilidade $(\mathrm{P}<0,01) ; \mathrm{CV} \%=8,49$.

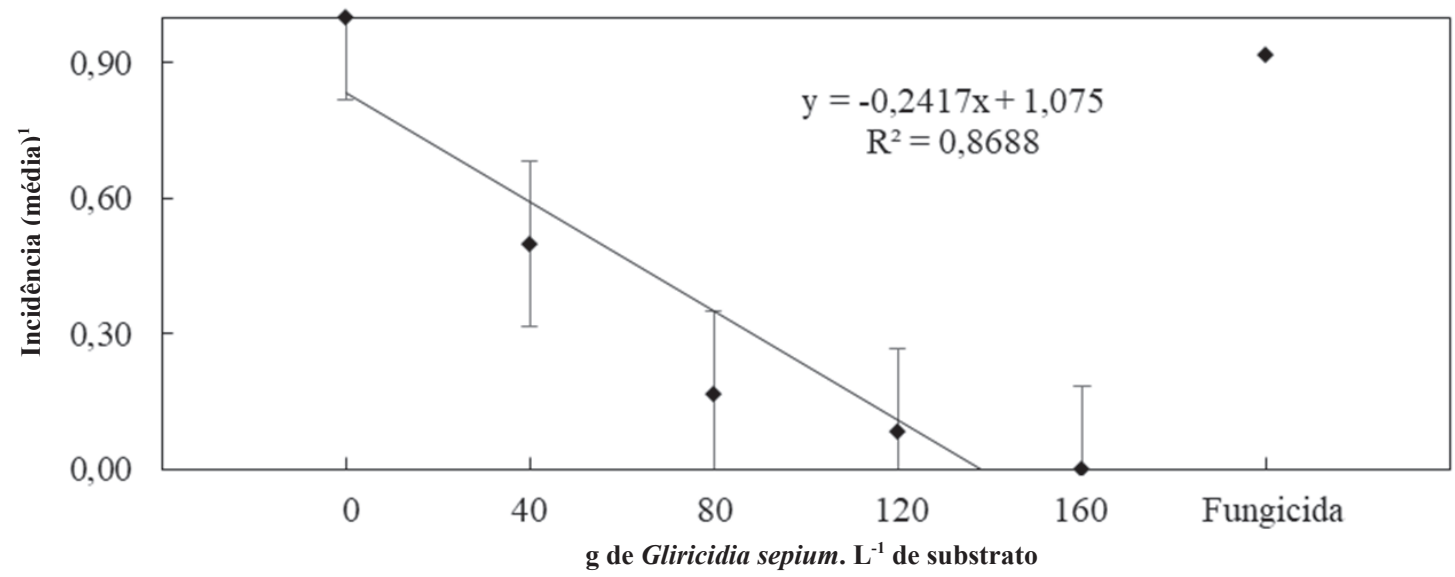

Teste F $72,06 * *$

Figura 5. Relação entre doses de Gliricidia sepium, incorporada ao substrato, e incidência média da podridão-de-escleródio em cubiu, aos 77 dias após o transplante. Manaus, Inpa, 2017. ${ }^{1}$ Média da incidência da doença correspondente a três repetições com quatro plantas de cubiu por repetição, significativa ao nível de $1 \%$ de probabilidade $(\mathrm{P}<0,01) ; \mathrm{CV} \%=8,97$.

do experimento (77 dias do transplante) (Figura 6).

A relação entre doses de G. sepium e área abaixo da curva de progresso da doença (AACPD) observadas na análise de regressão linear foram significativas $(\mathrm{P} \leq 0,01)$. A redução da incidência da podridão-de-escleródio foi proporcional ao aumento da dose de G. sepium incorporada ao substrato (Figura 7).

Avaliação da densidade do inóculo no substrato antes e após a incorporação do material vegetal no segundo experimento

Aos 20 dias após a infestação do substrato a população média de propágulos no substrato foi 32 UFC.100 g de substrato $^{-1}$, considerando a eficiência de $66,67 \%$ do método de detecção usado. Corrigindo para $100 \%$, em $100 \mathrm{~g}$ de substrato haveriam 80 escleródios.

A relação entre doses de biomassa de G. sepium e número de propágulos de $S$. rolfsii observadas na análise de regressão linear foram significativas $(\mathrm{P} \leq 0,01)$. Aos 77 dias do transplante verificou-se uma redução na população de propágulos de S. rolfsii de $20 \%$ com a incorporação de 142 $\mathrm{g}$ de $G$. sepium. $\mathrm{L}^{-1}$ de substrato (42,65 UFC. $100 \mathrm{~g}$ de substrato ${ }^{-1}$ em $66,67 \%$ de detecção, e corrigindo para $100 \%, 64$ UFC.100 g de substrato ${ }^{-1}$ ) em comparação à população no início do experimento (Figura 8).

Os resultados obtidos neste trabalho abrem a possibilidade de incorporação de leguminosas específicas no solo ou no substrato de plantio, para o manejo da podridão-de-escleródio em cubiu. Estudos em condições de campo e com a incorporação de outras doses das leguminosas ao substrato poderão definir a dose mais efetiva a ser usada no controle dessa doença. Esta alternativa de manejo da podridão-deescleródio, em cubiu, é ambientalmente sustentável e facilmente acessível aos agricultores locais. 


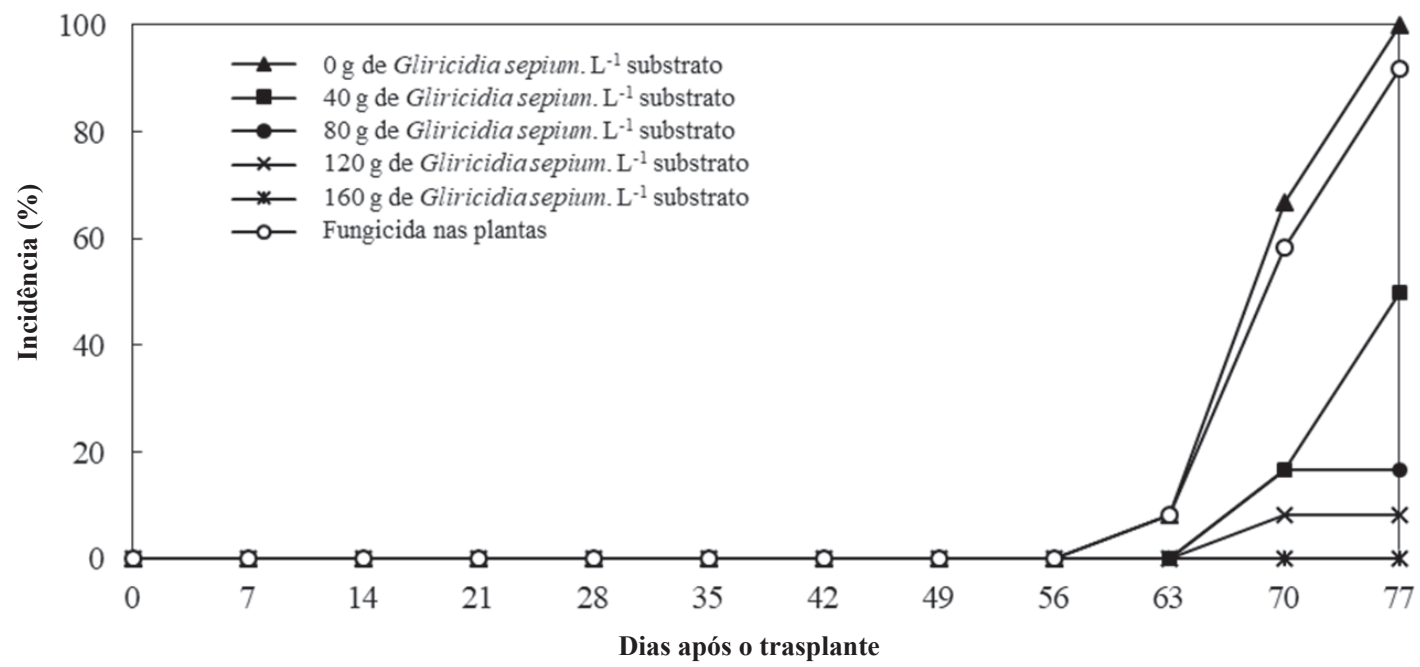

Figura 6. Curvas de progresso da incidência da podridão-de-escleródio em cubiu cultivado em substrato infestado com Sclerotium rolfsii e acrescido de quatro doses de Gliricidia sepium ou tratado com $9 \mathrm{ml}$ da solução [concentração de $70 \mathrm{~g}$ (p.c.) por 100 L de água] do fungicida Viper 700. Manaus, Inpa, 2017.

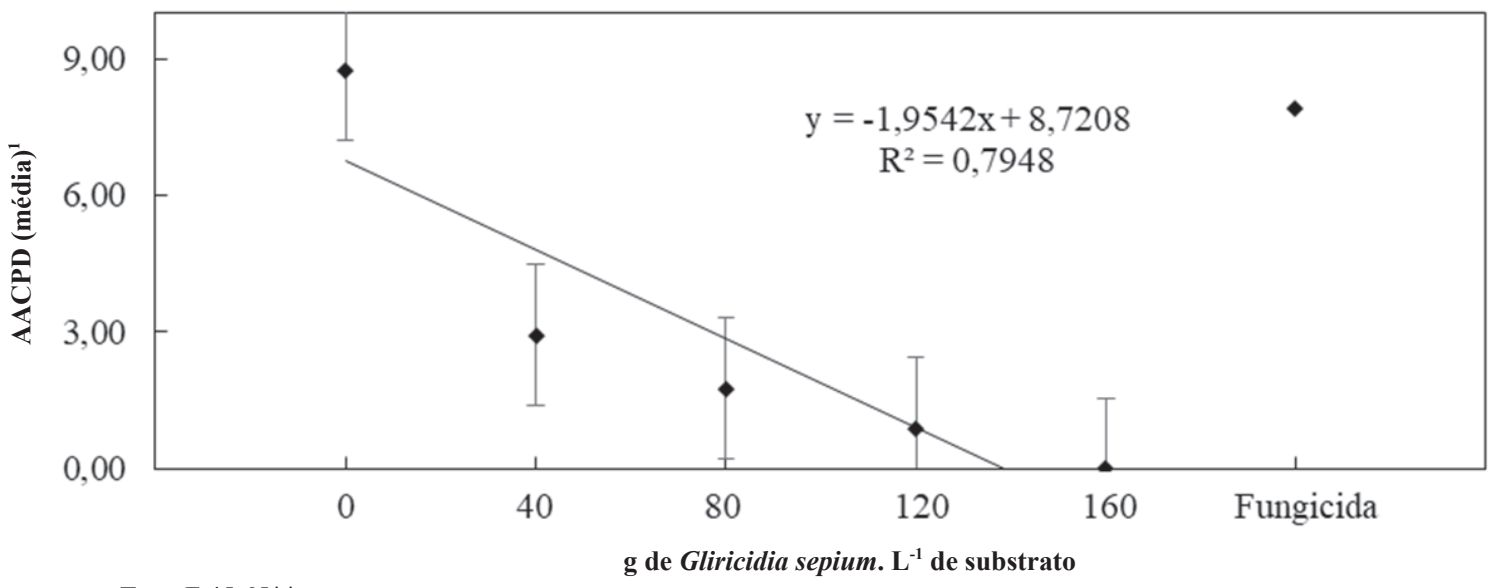

Teste F $45,65^{* *}$

Figura 7. Relação entre doses de G. sepium, incorporada ao substrato, e área abaixo da curva de progresso da doença (AACPD) da podridão-de-escleródio em cubiu. Manaus, Inpa, 2017. ${ }^{1}$ Média da área abaixo da curva de progresso da doença correspondente a três repetições com quatro plantas de cubiu por repetição, significativa ao nível de $1 \%$ de probabilidade $(\mathrm{P}<0,01) ; \mathrm{CV} \%=27,24$.

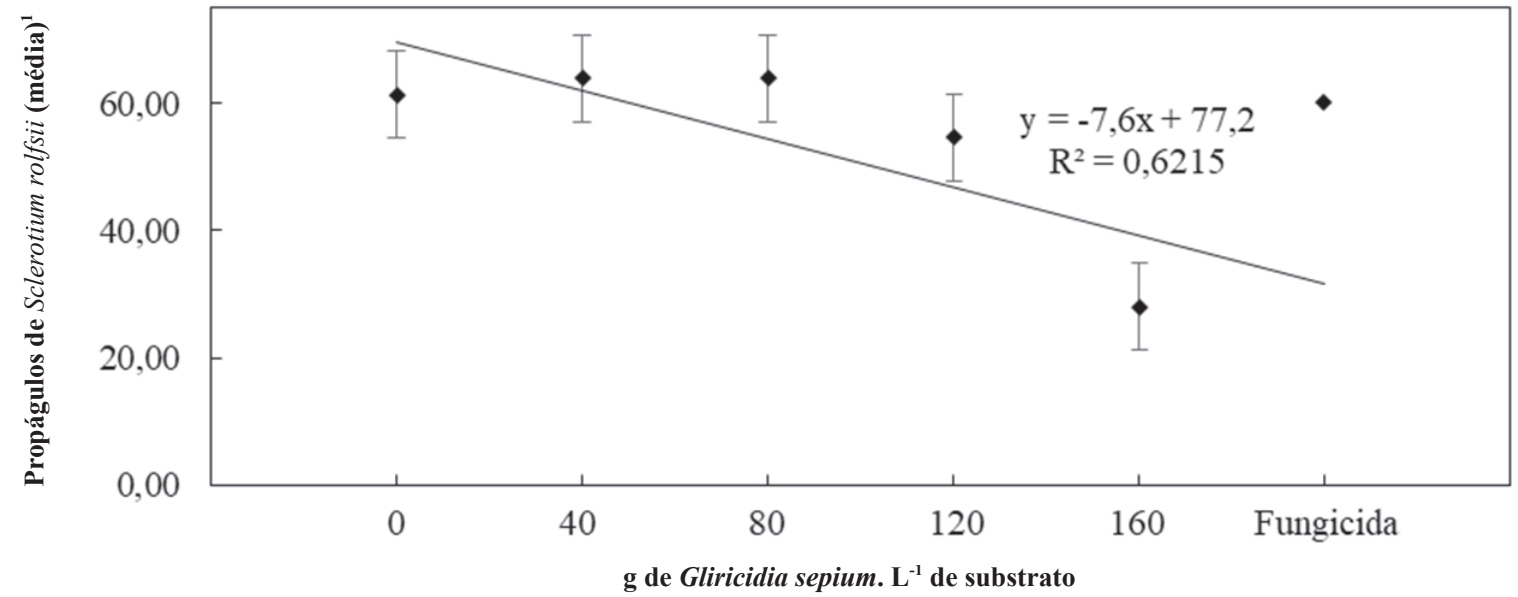

Teste F $27,02 * *$

Figura 8. Relação entre doses de G. sepium, incorporada ao substrato, e número de propágulos de $S$. rolfsii em $100 \mathrm{~g}$ de substrato, 77 dias após o transplante das mudas de cubiu. Manaus, Inpa, 2017. ${ }^{1}$ Média de colônias de S. rolfsii em três repetições, significava ao nível de $1 \%$ de probabilidade $(\mathrm{P}<0,01)$; $\mathrm{CV} \%=7,93$ 


\section{AGRADECIMENTOS}

A Fapeam pela concessão da bolsa de estudos. Ao Inpa pela oportunidade de realização da pesquisa.. Aos orientadores pelos ensinamentos, e aos técnicos e aos colegas do Inpa, pelo auxílio.

\section{REFERÊNCIAS}

1. Barbosa, R. N. T.; Halfeld-Vieira, B. A.; Nechet, K. L.; Souza, G. R. Método para inoculação de Sclerotium rolfsii em tomateiro. Revista Agroambiente, 4(1): 49-52, 2010.

2. Campbell, C. L.; Madden, L.V. Introduction to plant disease epidemiology. New York: John Wiley \& Sons, 1990, 532 p.

3. Chacha, M.; Bojase-Moleta, G.; Majinda, R. R. T. Antimicrobial and radical scavenging flavonoids from the stem wood of Erythrina latissima. Phytochemistry, New York, 66: 99-104, 2005.

4. Coelho Netto, R. A.; Ferreira, A. A. B.; Noda, H. Manejo da podridão-de -Sclerotium em pimentão em um argisolo no Amazonas. Acta Amazonica, Manaus, 43(3): 315 - 322, 2013.

5. Cruz, S. M. C.; Rodrigues, A. A.; Silva, E. K. C.; Oliveira, L. J. M. G. Supressividade por incorporação de resíduo de fabáceas no controle da fusariose do tomateiro. Summa Phytopathologica, São Paulo, 39(3): $180-185,2013$

6. Guerra, Y. L.; Oliveira, T. A. S.; Laranjeira, D.; Lima, L. M.; Melo Filho, P. A.; Santos, R. C. Control of Sclerotium rolfsii in peanut by using Cymbopogon martinii essential oil. African Journal of Microbiology Research, África, 9(27): 1684-1691, 2015.

7. Herforth, A. Anti-fungal plants of the Peruvian Amazon: A survey of ethnomedical uses and biological activity. Emanations from the Rainforest and the Caribean. New York: Cornell University, 68 p, 2002.

8. Lazarovits, G. Management of soil-borne plant pathogens with organic soil amendments: a disease control strategy salvaged from the past. Canadian Journal Plant Pathology, Canada, 23: 1-7, 2001.

9. Pires, A. M. B.; Silva, P. S.; Nardelli, P. M.; Gomes, J. C.; Ramos, A. M. Caracterização e processamento de cubiu (Solanum sessiliflorum). Ceres, Viçosa, 53(307): 309-316, 2006.
10. Rodríguez-Kábana, R.; Kokalis-Burelle, N.; Robertson, D. G.; King, P. S.; Wells, L. W. Rotations with coastal bermudagrass, cotton and bahiagrass for management of Meloidogyne arenaria and southern blight in peanut. Journal of Nematology, Orlando, 26: 665-668, 1994.

11. Rossi, C. E. Adubação verde no controle de nematóides. Agroecologia hoje, São Paulo, 2(14): 26-27, 2002.

12. Sharma, R. D. Adubação verde no controle de fitonematóides. In: Carvalho, A. M.; Amabile, R. F. Cerrado: adubação verde. Embrapa Cerrado, Planaltina, p. 237-264, 2006.

13. Silva Filho, D. F. Cocona (Solanum sessiliflorum Dunal) cultivo e utilizacion. Secretaria Pro-Tempore, Tratado de Cooperacion Amazonica, Caracas, 114 p, 1998.

14. Souza, L. A. G. Fabáceas para adubação verde na terra firme e na várzea da Amazônia central: um estudo em pequenas propriedades rurais em Manacapuru. Instituto Nacional de Pesquisas na Amazônia, Manaus, 40 p, 2012

15. Stone, A. G.; Scheuerell, S. J.; Darby, H. M. Suppression of soilborne diseases in field agricultural systems: organic matter management, cover cropping, and other cultural practices. In: Magdoff, F.; Weil, R. R. Soil Organic Matter in Sustainable Agriculture, Estados Unidos, p. 132-164, 2004.

16. Tomazeli, V. N.; Santos, I.; Morales, R. G. F. Resíduos orgânicos para o controle das doenças do feijoeiro causadas por Sclerotium rolfsii. Ambiência, Guarapuava, 7(1): 65-74, 2011.

17. Torrealba, S. Cuantificación de metabolitos secundarios en extractos etanólicos de Gliricidia sepium (Jacq.) Steud y Calotropis procera (Ait.) Ait.F. y el efecto de dichas plantas sobre el desarrollo in vitro de Sclerotium rolfsii. 2006.59 p. Trabalho de conclusão de curso - Agronomia, Universidad Centroccidental "Lisandro Alvarado", Barquisimeto, Venezuela.

18. Urdaneta, L.; Sanabria, M. E.; Rodríguez, D.; Camacaro, M. P. Grupos de metabolitos secundarios del extracto etanólico de Gliricidia sepium y su potencial antifúngico sobre Colletotrichum acutatum. Interciencia, Caracas, 38(6): 449-454, 2013.

19. Viana, F. M. P.; Souza, N. L. Controle do tombamento de plântulas de feijoeiro causado por Sclerotinia sclerotiorum com a incorporação de matéria orgânica ao substrato. Summa Phytopathologica, São Paulo, 26(1): 94-97, 2000 